\title{
Determination of the Corrosion Inhibition Effect of Terminalia Ivorensis Leaves Extract on Galvanized and Mild Steel in Sulphuric Acid Media
}

\author{
Maduelosi Ngozi Jane*, Timothy Micheal Nakara \\ Department of Chemistry, Rivers State University, Port Harcourt, Nigeria \\ Email address: \\ janemaduelosi@yahoo.com (M. N. Jane) \\ ${ }^{*}$ Corresponding author \\ To cite this article: \\ Maduelosi Ngozi Jane, Timothy Micheal Nakara. Determination of the Corrosion Inhibition Effect of Terminalia Ivorensis Leaves Extract on \\ Galvanized and Mild Steel in Sulphuric Acid Media. American Journal of Physical Chemistry. Vol. 8, No. 1, 2019, pp. 11-16. \\ doi: 10.11648/j.ajpc.20190801.12
}

Received: October 31, 2018; Accepted: December 20, 2018; Published: March 27, 2019

\begin{abstract}
The susceptibility of metals to corrosion due to attack by their environment has necessitated the search for corrosion inhibitors which can protect the metals and also be friendly with the environment. In this research, corrosion inhibition study of Terminalia ivorensis leaves extract on galvanized and mild steel in $1.0 \mathrm{M}$ Sulphuric acid was carried out to determine the corrosion inhibition ability of the leaves extract on the metals using weight loss method in three different concentrations $(15 \mathrm{~g} / \mathrm{l}, 10 \mathrm{~g} / \mathrm{l}$ and $5 \mathrm{~g} / \mathrm{l})$ of the extract and the acid solution. The metals were immersed in the solution for a period 432 hours. The weight loss of the metals was checked at 72 hours intervals. The results obtained reveal that there was decrease in weight loss of the metals immersed in the solution with the extract which indicates that the extract is a good corrosion inhibitor for galvanized and mild steel in sulphuric acid. The inhibition efficiency increased with increase in extract concentration at the temperature of study (ambient temperature). Maximum inhibition efficiency of $92.47 \%$ on mild steel and $82.10 \%$ on galvanized steel were obtained at the optimum concentration of the extract $(15.0 \mathrm{~g} / \mathrm{l})$. The inhibitive action was attributed to the presence of some notable phytochemical components of the leaves which possessed lone pairs of electrons that gave oxidative protection to the metals. It was observed that the protection by the extract was as a result of the adsorption of the extract on the metals and the experimental data obtained revealed that the adsorption followed Langmuir adsorption isotherm.
\end{abstract}

Keywords: Terminalia Ivorensis, Galvanized Steel, Mild Steel, Sulphuric Acid, Corrosion, Inhibitors, Metals

\section{Introduction}

Corrosion poses a big problem wherever metal is used. Its problems on metals are destructive, resulting to mechanical failure and devaluation of products. It causes degradation and eventually failure of components and systems in industries.

The problems of corrosion attack on metals have necessitated the use of corrosion inhibitors. Corrosion inhibitors are chemicals (synthetic or natural), which when added in small amounts to an environment, decreases the rate of attack by the environment on metals [3]. Inorganic substances used for corrosion inhibition include: phosphate, chromate, silicates, borates, tungstates, molybdates and arsenate [13]. Their use as corrosion inhibitors is diminishing due to their cost, non- biodegradability, strict environmental regulation and toxic effects on human and animal lives. Consequently, there exists the need for their replacement with green corrosion inhibitor.

Green corrosion inhibitors are extracts from plant roots, leaves, stems or backs that are used to inhibit or reduce corrosion. These plant extracts are biodegradable and contain no heavy metal that could be toxic to the environment.

Several works have been published on corrosion inhibition effects of plants extracts by earlier researchers [1, 3, 5, 6, 8-11, $13,14]$. Plant extracts reduce corrosion rate by adsorption of ions/molecules onto the metal surface and increasing or decreasing the anodic and/or cathodic reaction. The effectiveness of plant extracts as corrosion inhibitor is attributed to the presence of some phytochemicals like essential oils, 
tannins, pigments, steroids, terpenes, flavones, possessing some notable functional groups like nitrogen, oxygen as well as multiple bonds in their molecules. These serve as active centers for the process of adsorption on metal surface.

Most organic inhibitors adsorb on the metal surface by displacing water molecules on the surface and forming a compact barrier as illustrated below:

$$
\mathrm{O}_{2}+\mathrm{N}_{2} \mathrm{H}_{4} \rightarrow 2 \mathrm{H}_{2} \mathrm{O}+\mathrm{N}_{2}
$$

Oxygen in the above equation (a common corrosive agent) is removed by a reductive inhibitor, hydrazine and convertedto water [4].

Study of the corrosion inhibitive action of Terminalia ivorensis leaves extract on galvanized and mild steel in Sulphuric acid investigated the inhibitive action of the leaves extract on both galvanized and mild steel in $1.0 \mathrm{M} \mathrm{H}_{2} \mathrm{SO}_{4}$ solution using weight loss method. Terminalia ivorensis (also called Ivory Coast almond or Black Afara) is a specie of tree in the family Combretaceae. It is found in Cameroon, Ivory Coast, Ghana, Guinea, Liberia, Sierra Leon and Nigeria. It is a large deciduous forest tree ranging in height from 15 to 45 meter.

\section{Method}

\subsection{Preparation of Metal Coupons}

Galvanized and mild steel coupons used for this study were obtained from mechanical workshop of the Rivers State University, Port Harcourt, Nigeria. They were of $1.2 \mathrm{~mm}$ thickness and were mechanically cut into rectangular coupons of dimensions $40 \mathrm{~mm} \times 50 \mathrm{~mm}$.

The coupons were drilled at the center-top for passage of thread and were mechanically scrubbed and cleaned with sand-paper to expose the clean-shinning surface. They were washed with distilled water, degreased in ethanol, dried in acetone and then stored in desiccator for the corrosion study.

\subsubsection{Preparation of Plant Extract}

The leaves of Terminalia ivorensis (commonly called Black Afara) were collected from Rivers State University, Port Harcourt and identified by a botanist. The extract was got through solvent extraction method with methanol.

\subsubsection{Preparation of Different Concentrations of the Plant Extract}

Test solutions of $5.0 \mathrm{~g} / \mathrm{l}, 10.0 \mathrm{~g} / \mathrm{l}$, and $15.0 \mathrm{~g} / \mathrm{l}$ of the extracts in $1.0 \mathrm{M} \mathrm{H}_{2} \mathrm{SO}_{4}$ were prepared. Blank solutions (that is, solutions of acids without the extract) were also prepared and all were used for the corrosion inhibition test.

\subsection{Weight Loss Method}

The weight loss determinations were performed by immersion of the pre-weighed mild steel and galvanized steel coupons into the test solutions. Each coupon was retrieved after 72 hours interval for 18 days, brushed, cleaned and dried in acetone, and re-weighed. The weight loss of the coupons was obtained using the equation below.

$$
\mathrm{WL}=\mathrm{WI}-\mathrm{WF}
$$

Where, WL is the weight loss

WI, the initial weight of the coupon before immersion.

WF, the final weight of the coupon after immersion.

\subsubsection{Corrosion Rate}

The expression for measurement of Corrosion Rate (C. R.) in millimeters penetration per year $(\mathrm{mm} / \mathrm{yr}$.) was used to measure corrosion rate (C. R.) for the specimens as expressed in equation 3 below.

$$
\text { C. R. }=\frac{87.6 W L}{\rho A T}
$$

Where WL, is the corrosion weight loss of the metals (in $\mathrm{mg}), \rho$ is the density of the coupons $\left(\mathrm{g} / \mathrm{cm}^{3}\right), \mathrm{T}$, is the exposure time (in hours), $\mathrm{A}$ is the surface area (in $\mathrm{cm}^{2}$ ) obtained from equation 4 below.

$$
\mathrm{A}=2(\mathrm{BL}+\mathrm{LW}+\mathrm{BW})
$$

Where $\mathrm{B}, \mathrm{L}$ and $\mathrm{W}$ are the breath, lengthand width of the coupons respectively.

\subsubsection{Percentage Inhibition Efficiency (\%IE)}

The percentage inhibition efficiency ( $\%$ IE) was calculated using the relation in equation 5 below.

$$
\% \mathrm{IE}=\frac{C R B L K-C R I N H}{C R B L K} \times 100
$$

Where $\mathrm{CR}_{\mathrm{BLK}}$ and $\mathrm{CR}_{\mathrm{INH}}$ represents corrosion rates in the absence and presence of the inhibitor respectively.

\subsubsection{Degree of Surface Coverage $(\theta)$}

The fractional surface coverage was calculated using the relation in equation 6 .

$$
\Theta=\% \mathrm{IE} / 100
$$

\subsubsection{Film Attractive Power}

From the degree of surface coverage at a given inhibitor concentration, the film attractive power equation was computed using equation 7 below.

The conventional form of the Langmuir isotherm is $\frac{\theta}{1-\theta}=$ $\mathrm{KC}$, rearranging this gives $\frac{C}{\theta}=\frac{1}{k}+\mathrm{C}$

$$
\text { Kads }=\frac{\theta}{C(1-\theta)}
$$

Where Kads is the film attractive power or equilibrium constant of adsorption, $\theta$ is the degree of surface coverage, $\mathrm{C}$ is the concentration of inhibitor.

\section{Results}

\subsection{Result of Phytochemical Analysis}

The results of the investigation are presented in the tables and figures below.

Table 1 gives the phytochemical components that are presence and absence in the plant extract using the methods 
described by [12].

Table 1. Phytochemical Components of Terminalia ivorensis plant extract.

\begin{tabular}{ll}
\hline Tests & Results \\
\hline Alkaloids & $+\mathrm{ve}$ \\
Cardiac glycosides & $+\mathrm{ve}$ \\
Carotenoids & $+\mathrm{ve}$ \\
Flavonoids & $+\mathrm{ve}$ \\
Phlobatannins & $-\mathrm{ve}$ \\
Saponins & $+\mathrm{ve}$ \\
Terpenoids & $+\mathrm{ve}$ \\
Tannins & $+\mathrm{ve}$ \\
\hline
\end{tabular}

\subsection{Results of the Corrosion Study}

Table 2. Corrosion rate, Surface coverage and Inhibition efficiency of the extract on mild steel in $1.0 \mathrm{M} \mathrm{H}_{2} \mathrm{SO}_{4}$.

\begin{tabular}{|c|c|c|c|c|c|c|c|c|c|c|c|c|c|c|c|c|c|c|}
\hline \multirow{2}{*}{$\begin{array}{l}\text { Sample } \\
\text { (g/L) }\end{array}$} & \multicolumn{6}{|c|}{ Corrosion Rate (CR) } & \multicolumn{6}{|c|}{ Surface Coverage ( $\theta$ ) } & \multicolumn{6}{|c|}{ Inhibition Efficiency (IE) } \\
\hline & $72 \mathrm{hr}$ & $144 \mathrm{hr}$ & $216 \mathrm{hr}$ & $288 \mathrm{hr}$ & $360 \mathrm{hr}$ & $432 \mathrm{hr}$ & $72 \mathrm{hr}$ & $144 \mathrm{hr}$ & $216 \mathrm{hr}$ & $288 \mathrm{hr}$ & $360 \mathrm{hr}$ & $432 \mathrm{hr}$ & $72 \mathrm{hr}$ & $144 \mathrm{hr}$ & $216 \mathrm{hr}$ & $288 \mathrm{hr}$ & $360 \mathrm{hr}$ & $432 \mathrm{hr}$ \\
\hline Blank & 15.55 & 15.15 & 14.77 & 14.41 & 14.08 & 13.01 & 0.00 & 0.00 & 0.00 & 0.00 & 0.00 & 0.00 & 0.00 & 0.00 & 0.00 & 0.00 & 0.00 & 0.00 \\
\hline 5 & 8.71 & 3.68 & $3 . .63$ & 3.58 & 3.12 & 2.79 & 0.76 & 0.76 & 0.77 & 0.75 & 0.78 & 0.79 & 76.14 & 75.71 & 77.31 & 75.16 & 77.84 & 78.55 \\
\hline 10.0 & 2.94 & 2.67 & 2.38 & 2.10 & 1.82 & 1.49 & 0.81 & 0.82 & 0.83 & 0.85 & 0.87 & 0.89 & 80.97 & 82.38 & 83.89 & 85.43 & 87.07 & 88.55 \\
\hline 15.0 & 2.39 & 3.73 & 1.45 & 1.24 & 1.09 & 0.98 & 0.85 & 0.89 & 0.90 & 0.91 & 0.92 & 0.92 & 84.63 & 88.58 & 90.18 & 91.39 & 92.26 & 92.47 \\
\hline
\end{tabular}

Table 3. Corrosion rate, Surface coverage and Inhibition efficiency of the extract on galvanized steel in 1.0M H2SO4.

\begin{tabular}{|c|c|c|c|c|c|c|c|c|c|c|c|c|c|c|c|c|c|c|}
\hline \multirow{2}{*}{$\begin{array}{l}\text { Sample } \\
\text { (g/L) }\end{array}$} & \multicolumn{6}{|c|}{ Corrosion rate (CR) } & \multicolumn{6}{|c|}{ Surface Coverage $(\boldsymbol{\theta})$} & \multicolumn{6}{|c|}{ inhibition Efficiency (IE) } \\
\hline & $72 \mathrm{hr}$ & $144 \mathrm{hr}$ & $216 \mathrm{hr}$ & $288 \mathrm{hr}$ & Ohr & $432 \mathrm{hr}$ & $72 \mathrm{hr}$ & $144 \mathrm{hr}$ & $216 \mathrm{hr}$ & $288 \mathrm{hr}$ & $360 \mathrm{hr}$ & $432 \mathrm{hr}$ & $72 \mathrm{hr}$ & $144 \mathrm{hr}$ & $216 \mathrm{hr}$ & $288 \mathrm{hr}$ & $360 \mathrm{hr}$ & $432 \mathrm{hr}$ \\
\hline Blank & 11.54 & 36 & 7.74 & 7.34 & 6.68 & 6.11 & 0.00 & 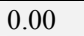 & .00 & 0.00 & 0.00 & 0.00 & 0.00 & 0.00 & 0.00 & 0.00 & 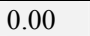 & 0 \\
\hline 5 & 2.55 & 2.55 & 2.69 & 2.76 & 2.63 & 2.33 & 0.78 & 0.70 & 0.65 & 52 & 0 & 0. & 90 & 50 & 25 & 40 & 63 & 61.87 \\
\hline $10 .($ & 2.18 & 1.72 & 1.56 & 1.40 & 1.31 & 1.14 & 0.81 & 0.80 & 0.80 & 0.81 & 0.80 & 0.81 & 11 & 79.43 & 79.84 & 80.93 & 80.39 & 81.34 \\
\hline 15.0 & 2.25 & 1.68 & 1.50 & 1.31 & 1.19 & 1.10 & 0.81 & 0.80 & 0.81 & 0.82 & 0.82 & 0.82 & 80.50 & 79.90 & 80.62 & 82.15 & 82.19 & 82.10 \\
\hline
\end{tabular}

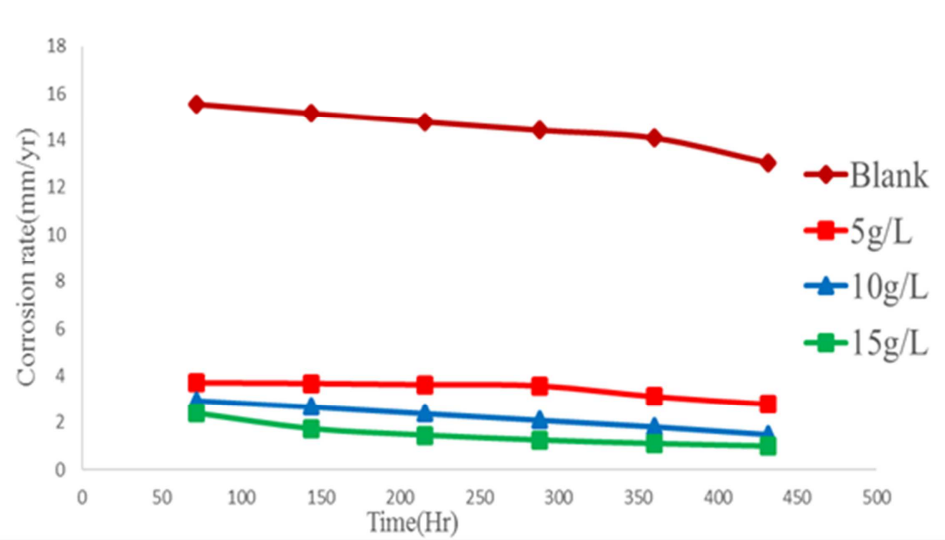

Figure 1. Plots of corrosion rate versus time of Mild steel in the various experimental solutions.

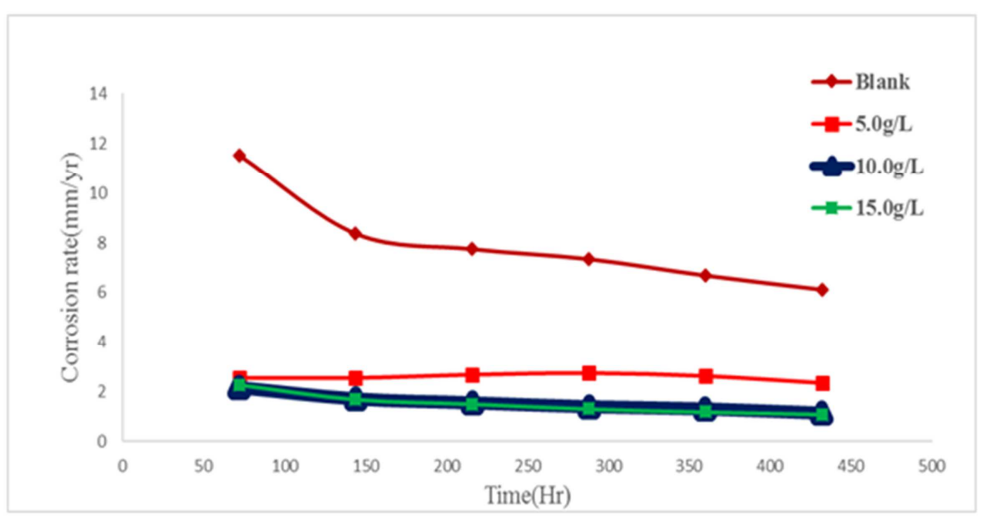

Figure 2. Plots of corrosion rate versus time curve of galvanized steel in the various experimental solutions. 
Maduelosi Ngozi Jane and Timothy Micheal Nakara: Determination of the Corrosion Inhibition Effect of Terminalia Ivorensis Leaves Extract on Galvanized and Mild Steel in Sulphuric Acid Media

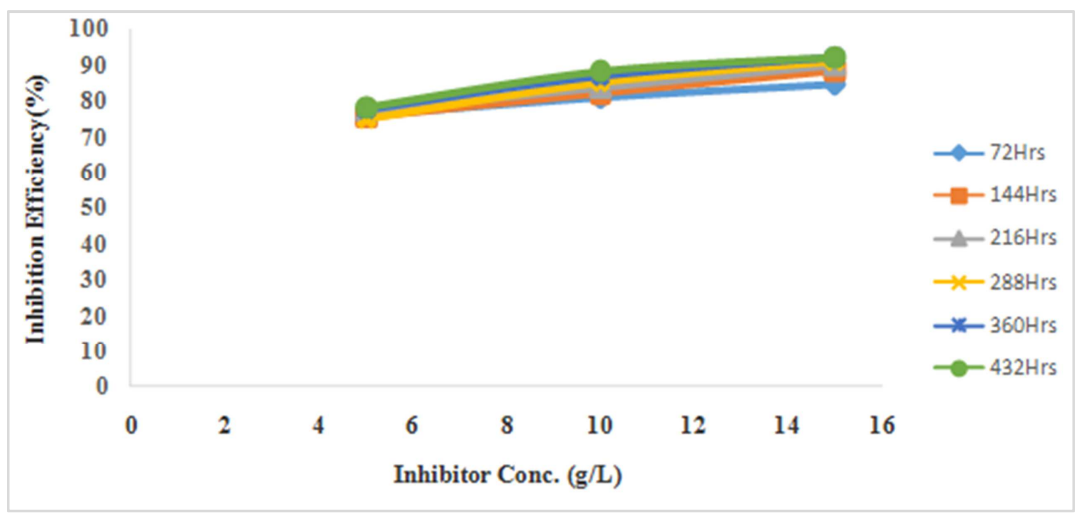

Figure 3. Variation of Percentage inhibition efficiency (\%IE) on mild steel with inhibitor concentration in $1.0 \mathrm{M} \mathrm{H}_{2} \mathrm{SO}_{4}$ at varying time.

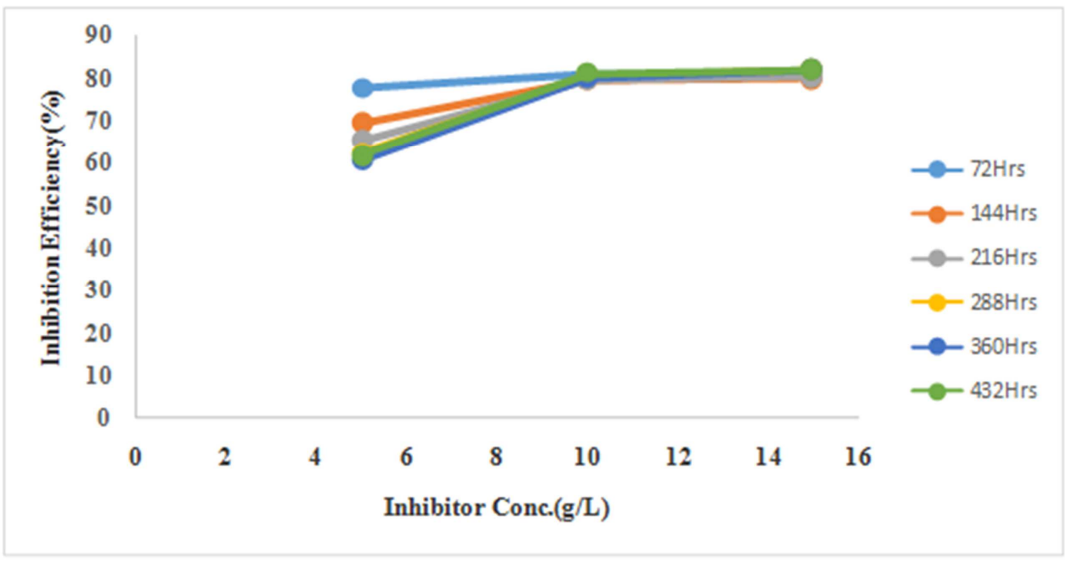

Figure 4. Variation of Percentage inhibition efficiency (\%IE) on galvanized steel with inhibitor concentration in $1.0 \mathrm{M} \mathrm{H}_{2} \mathrm{SO}_{4}$ at varying time.

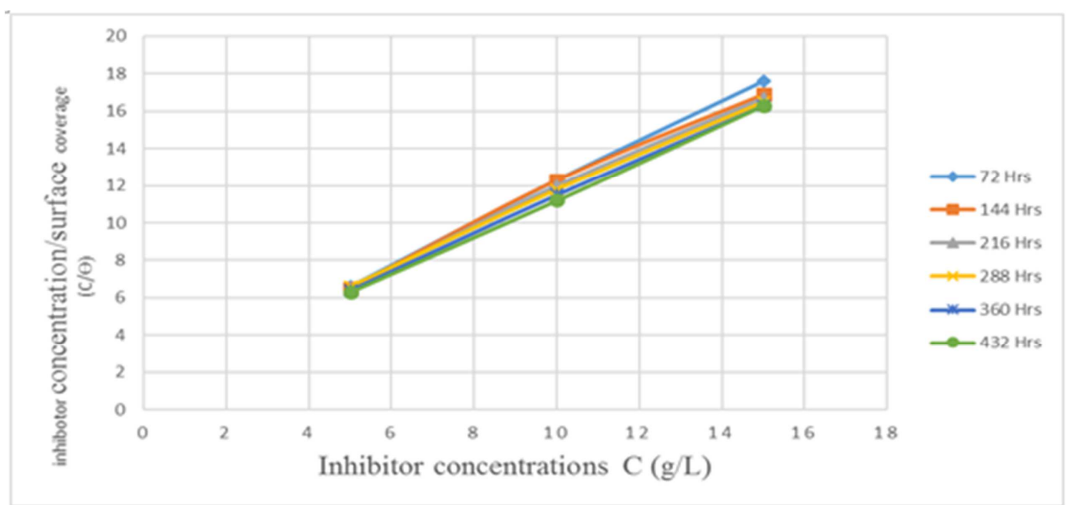

Figure 5. Langmuir Adsorption Isotherm for Terminalia ivorensis leaves extract in 1.0M H2SO4 on mild steel.

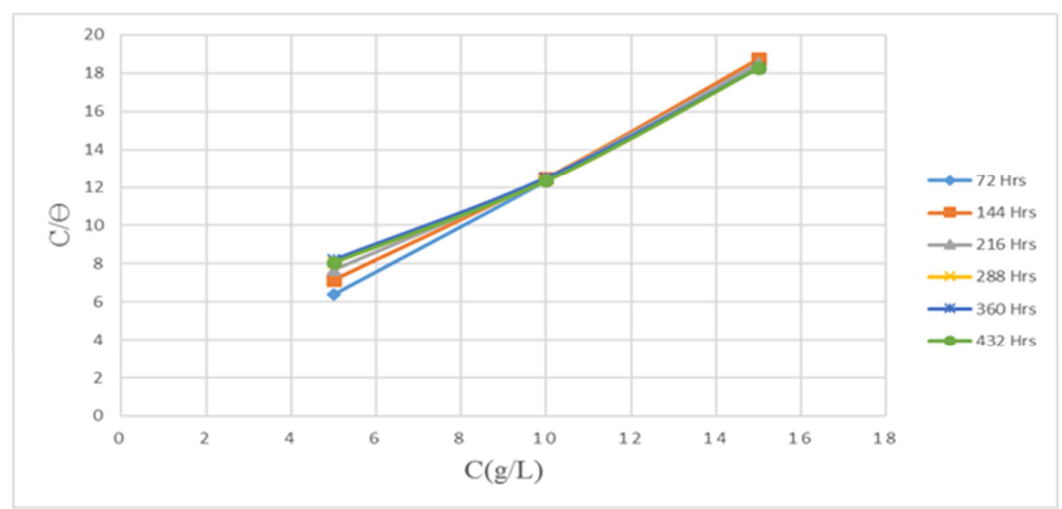

Figure 6. Langmuir Isotherm for Terminalia ivorensis leaves extract in 1.0M $\mathrm{H}_{2} \mathrm{SO}_{4}$ on galvanized steel. 


\section{Discussions}

The results in table 1 show the phytochemical compounds that are present in the extract (indicated by + sign) and those that are absent in the extract (indicated by - sign). Tables 2 and 3 show the effects of inhibitor concentrations of the extract on the corrosion rate, surface coverage and inhibition efficiency on the two metals studied in $1.0 \mathrm{M} \mathrm{H}_{2} \mathrm{SO}_{4}$ solutions.

Figures 1-4 show the graphs of corrosion rate and percentage inhibition efficiency against inhibitor concentration for the corrosion of both galvanized and mild steel in $1.0 \mathrm{M} \mathrm{H}_{2} \mathrm{SO}_{4}$ at different time intervals. The results show that corrosion rate decreased as the concentrations of the extract increased. On the other hand, it was observed that surface coverage and percentage inhibition efficiency increased with increase in the concentration of the extract in the samples. This is attributed to the adsorption of active ions<smiles>[R]Oc1cc2c(cc1OC)-c1c(C)c3ccc([R7])c([R2])c3c[n+]1CC2</smiles>

from the plant extract onto the surface of the metals and the formation of a co-ordinate covalent bond between the inhibitor and the metal surface. This leads to less contact of the metals with the acid environment and hence the increase in percentage inhibition efficiency and reduction in weight loss of the metal with time. Similar results have been reported earlier by references $[2,10,11]$.

The presence of functional groups like oxygen (O), nitrogen $(\mathrm{N})$ and sulphur $(\mathrm{S})$ in the molecules of the plant extract serves as the active centers for the adsorption of the inhibitor on the metal surface because of their high basicity and electron density. The availability of non-bonded (lone pair) electrons in the functional groups of the inhibitor molecules may have also facilitated electron transfer from inhibitor to the surface of the metal as revealed by earlier researcher [2].

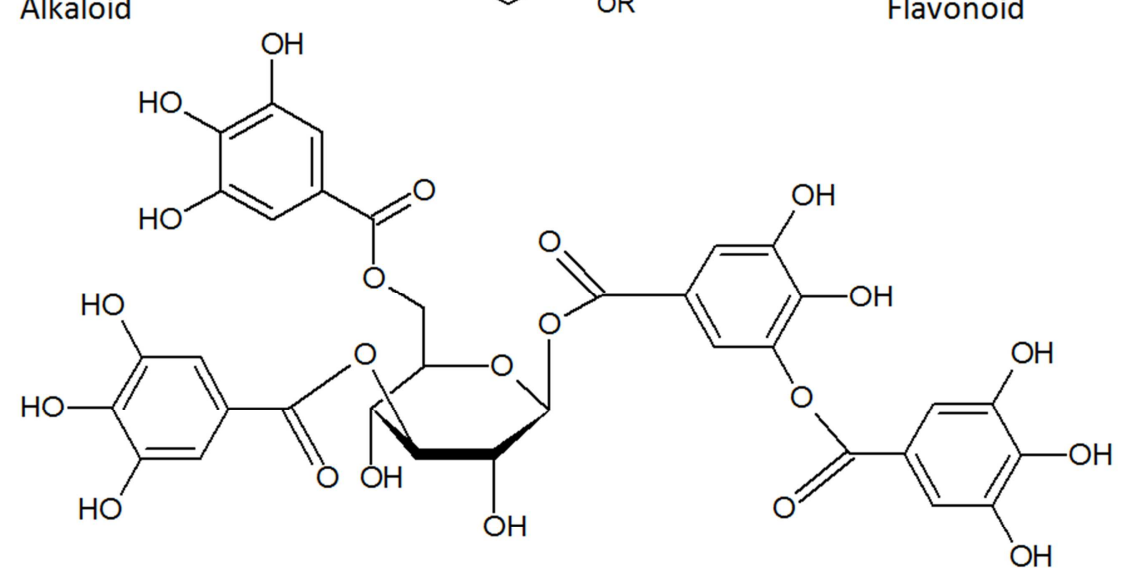<smiles>O=c1cc(-c2ccccc2)oc2ccccc12</smiles>

Tannin

Figure 7. Structures of Some Phytochemical Compouds Present in the Extract.

Figures 5 and 6 show the plots of $\mathrm{C} / \theta$ against concentration $\mathrm{C}$ where linear plots were obtained. The correlation coefficients suggest that the adsorption of the extract fitted best into Langmuir isotherm. The higher values of Kads indicate that inhibitors were strongly adsorbed on the metal surfaces. The adsorption method here is physical.

\section{Conclusions}

The results obtained in this study show that Terminalia ivorensis leaves extract has inhibitory properties and can serve as a good corrosion inhibitor for galvanized and mild steel in $1.0 \mathrm{M}$ acidic medium $\left(\mathrm{H}_{2} \mathrm{SO}_{4}\right)$. The inhibition efficiency increased with increase in concentration of the extract. The inhibitive action is attributed to the presence of phytochemical components in the extract. The percentage efficiency of the extract inhibition was more on mild steel than galvanized steel. The extract can serve as a good replacement for the toxic, non-biodegradable and costly organic and inorganic compounds used as corrosion inhibitors.

\section{References}

[1] Abdul-Amir, H. K., Abu, B. M., Leiqaa A. H., Ahmed, A. A., and Ahmed Y. M. (2014). Inhibition of Mild Steel Corrosion in Hydrochloric Acid Solution by New Coumarin. Materials. (7): 4335-4348. 
[2] Adesanmi A., (2015). Investigation of Corrosion Inhibition of Guava, Banana and Almond Plant Extract in $0.5 \mathrm{M}$ of $\mathrm{HCl}$ and $\mathrm{H}_{2} \mathrm{SO}_{4}$ Solution on Low Carbon Steel. Unpublished Postgraduate Dissertation, Ahmadu Bello University, Zaria, Nigeria.

[3] Al-Otaibi, M. S., Moyouf, A. M., Khan, M., Mousa, A. A., Al-Mazroba, S. A., and Alkhathlan, H. Z. (2014). Corrosion inhibitory action of some plant extracts on the corrosion of mild steel in acidic media. Arabian Journal of Chemistry. 7(3): 340-346.

[4] Http://www.wikipedia. Retrieved January $5^{\text {th }} 2017$. The free encyclopedia/corrosion inhibition.

[5] Ituen, E. B., Akaranta, O. and James, A. O. (2014). Inhibition of mild steel corrosion in sulphuric acid solution by extract of Curcuma longa rhizome. Proceedings of $37^{\text {th }}$ Annual International Conference of Chemical Society of Nigeria (CSN).

[6] Johnny, I. I., Ekong, N. J. and Okon, J. E. (2014). Phytochemical Screening and Anti-hyperglycemic Activity of Ethanolic Extract of Terminalia ivorensis and chev leaves on Albino Wister Rats. Global Advanced Research Journal of Medicine and Medical Science. 3(8): 186-189.

[7] Lebe, N., George N., Justus N., Ekekwe, N. and Peter E. (2016). Aqueous Extracts of Pentaclethra macrophylla Bentham Roots as Eco-Friendly Corrosion Inhibitor for Mild Steel in $0.5 \mathrm{M} \mathrm{KOH}$ Medium. International Journal of Materials and Chemistry. 6(1): 12-18.

[8] Loto, R. T., Loto, C. A. and Popoola A. P. I. (2012). Effect of Aminobenzene Concentrations on the Corrosion Inhibition of
Mild Steel in Sulphuric Acid. International Journal of Electrochemical Science. 7(2012): 7016-7032.

[9] Murugavel, S. C. and Gunavathy, N. (2011). Corrosion Inhibition Studies of Mild Steel in Acid Medium using Musa acuminata fruit peel. E-Journal of chemistry. 9(1): 487-495.

[10] Nwaugbo, C. M., Oforka, N. C. and James, A. O. (2014). The corrosion inhibition of mild steel in sulphuric acid solution by flavonoid (catachin) separated from Nypa fruticans wurmb leaves extract. Science Journal of Chemistry. 2(4): 491-496.

[11] Obike, A. L., Ajiwe, C. N. and Igwe, J. C. (2016). Corrosion inhibition and Adsorption Behaviour of Methanol extract of Spondias cytherea leaves on mild steel corrosion $5.0 \mathrm{M} \mathrm{H}_{2} \mathrm{SO}_{4}$. International Journal of Innovative Research in Science, Engineering and Technology. 5(6): 9501-9510.

[12] Odinga, T., Worlu-Wodo, Q. E. and Deekae, S. (2016). Bioprospective Screening of Ricinodendron heudelottii seeds. Journal of Analytical and pharmaceutical Research. 3(7): 2-3.

[13] Rani, B. E. A. and Basu, B. B. J (2012). Green inhibitors for corrosion protection of metals and alloy: An overview. International Journal of corrosion. 2012, (2012), 1-15.

[14] Sharma, S. K., Peter, A. and Obot, I. B. (2015). Potential of Azadirachta indica as a green corrosion inhibitor against mild steel, aluminium and tin: a review. Journal of Analytical Science and Technology. 6(26): 2-16. 